\title{
El egoísmo de los jóvenes de hoy responde a la necesidad de supervivencia
}

Diana Gladys Barimboim ${ }^{1}$

UADE

Ensayo original para ser publicado en el Journal de Ciencias Sociales, Revista Académica de la Facultad de Ciencias Sociales de la Universidad de Palermo.

Recibido: 5-6-2015

Aceptado: 2-9-2015

\section{RESUMEN}

Este ensayo intenta realizar una reflexión sobre las tendencias egoístas de los jóvenes entre 20 y 30 años de clase media y alta, estudiantes universitarios y terciarios de AMBA (Argentina).

Entendemos que dichas tendencias son el resultado de la necesidad de supervivencia en el siglo XXI. El esfuerzo por lograr sus metas de independencia económica los lleva a centrarse en sí mismos y en su propio desarrollo de carrera.

Sin posibilidades de realizar proyectos a futuro, sus ideales de libertad se proyectan en lograr objetos de consumo como, por ejemplo, viajar.

Pensamos la sintomatología endémica de la época, producto de un exacerbado narcisismo como forma defensiva frente a la angustia del vacío representacional del proyecto futuro en la cultura de la incertidumbre y de la banalidad de la injusticia social.

Palabras claves: Egoísmo, supervivencia, libertad, proyecto

Abstract: This essay tries to make a reflection about the selfish trend of young people between 20 and 30 years of class, medium and high, college students, and tertiary AMBA (Argentina).

We understand that these trends are the result of the need for survival in the XXI century. The effort to achieve their goals of economic independence leads them to have a self-centering attitude and on its own career development.

\footnotetext{
${ }^{1}$ Doctora en Psicología Social. Docente UADE. diana@barimboim.com
} 
Without possibility of future projects, their ideals of freedom are projected to achieve consumer objects such as: travel.

We think the endemic symptomology of this time, product of an exacerbated narcissism as a defensive way against the anguish of the representational emptiness of the future project in the culture of the uncertainty and the banality of social injustice.

Keywords: Selfishness, survival, freedom, project

\section{Introducción}

Se habla del egoísmo e individualismo de los jóvenes de hoy. Pensamos que esta categoría no reviste en los tiempos del hipercapitalismo un signo peyorativo sino un intento desesperado por lograr sobrevivir en una sociedad que no ofrece garantías de subsistencia, donde el mar de incertidumbres sobre el futuro y la apertura imaginaria de posibilidades ilimitadas brindada por la globalización genera un estado de ansiedad permanente.

Al hablar de jóvenes, no podemos pensar en una generalidad, sino en una multiplicidad de grupos que transitan el camino hacia la adultez, según la posición socioeconómica de la que provienen, la constitución de sus familias de origen, los grupos sociales a los que pertenecen, etc. En esta diversidad, nos encontramos ante la misma problemática social con un abanico que va desde los jóvenes "nini" (ni trabajan ni estudian), hasta aquellos que tratan de asegurarse su inclusión en el mercado laboral estudiando carreras terciarias y/o universitarias, buscando un empleo que les brinde una independencia económica.

Nuestra reflexión versará sobre este último grupo. Para ello realizamos una investigación de carácter exploratorio en el Instituto de Ciencias Sociales y Disciplinas Proyectuales (NSOD) de la Universidad Argentina de la Empresa (UADE), con jóvenes de clase media del Área Metropolitana de Buenos Aires (AMBA), de entre 20 y 30 años. Tomamos 800 encuestas y 30 entrevistas semidirigidas.

Como técnica de recolección de datos se ha privilegiado la realización de una encuesta realizada ad hoc a partir de la combinación de escalas actitudinales de Lickert de validez y confianza ampliamente comprobada. La encuesta contendrá escalas del Inventario de Dimensiones de la Adultez Emergente (IDEA, Reifman, Arnett y Colwell, 2007). Las escalas se combinarán con otras construidas a la luz del problema de investigación, adaptadas del Inventario. La toma de las encuestas se ha realizado de forma presencial. Para la metodología cualitativa seguimos a Vasilachis de Gialdino (1993), bajo el supuesto básico del paradigma 
interpretativo como "la necesidad de comprensión del sentido de la acción social en el contexto del mundo de la vida y desde la perspectiva de los participantes" (Vasilachis de Gialdino, 1993, p. 9).

Detectamos que ponen todo su ahínco en terminar su carrera profesional para lograr un empleo bien remunerado. Esto se encuentra en el centro de sus preocupaciones al igual que sus anhelos de libertad. Correlativamente con estas motivaciones, surge el temor por la inestabilidad laboral y la imposibilidad de imaginar un proyecto a largo plazo.

Consideran que tienen que terminar una formación terciaria o universitaria para mejorar sus posibilidades de empleo, aunque muchos de ellos desearían realizar un emprendimiento individual, ya que no confían en los trabajos que pudieran lograr en relación de dependencia. También imaginan que podrían encontrar un futuro tanto en su lugar de residencia como en cualquier otro lugar del mundo: el punto es la búsqueda incansable de una oportunidad para poder independizarse económicamente y así lograr un estado de bienestar y felicidad.

Los movimientos espasmódicos que realizan son erráticos, ya que muchas veces cambian de empleo hasta por las mismas o peores condiciones salariales, pero con la

ilusión de una promesa de desarrollo en la organización. Cuestión que los lleva, al poco tiempo, a cambiar de empleo reanudando el ciclo repetitivo de ilusión/decepción. Gil Calvo sostiene al respecto: "Hoy estaríamos frente a la típica imagen de la sociedad liberal, atomizada, e individualista, donde todos buscan lucrarse persiguiendo su propio interés personal" (Gil Calvo, E., 1993, p.45).

Los jóvenes no tienen interés en participar en proyectos políticos o solidarios, ya que tienen toda su energía puesta en sí mismos, para desarrollar su propia carrera profesional, lo que denota un interés eminentemente egoísta.

No confían en ningún tipo de apoyo o continencia que pudiera provenir de la sociedad o de los proyectos políticos vigentes. Sin embargo, sigue siendo fuente de reaseguro tanto afectivo como económico la familia de origen, lo que dificulta el desasimiento de las figuras parentales en el camino hacia la madurez. Esto reafirma la idea de un ciclo de adolescencia tardía que implica un incremento del narcisismo, como característica evolutiva propia en su trabajo por consolidar la autonomía identitaria.

Además pone en cuestionamiento "la caída de la Institución Familia" de la que se habla como característica de la Posmodernidad. Consideramos que si bien ha habido un cambio en la representación social de familia, y existen hoy nuevas configuraciones familiares, parece ser que las figuras parentales siguen subsistiendo como figuras de apego afectivo y económico en este grupo etario, frente al desierto de garantías que surge en el mercado laboral y el paradigma de inclusión/exclusión social. 
Así pensamos que la economía y la cultura, a través de la historia se han influido recíprocamente y han generado los diferentes malestares epocales para el hombre, productor y producido por ellas. Intentamos en este ensayo, tratar de comprender, la característica egoísta de los jóvenes de hoy como un efecto de la posmodernidad desde la psicología social crítica y el psicoanálisis. Característica que es efecto del intento de supervivencia de estos jóvenes en un mundo donde rige la banalidad de la injusticia social.

Las reacciones sociales han experimentado una evolución hacia el lado de la tolerancia, el sufrimiento, la infelicidad y la injusticia. Esta evolución se caracterizaría por la atenuación de las reacciones de indignación, cólera y movilización colectiva, conducentes a una acción a favor de la solidaridad y la justicia (Dejours, 2006, p.19).

Por lo que consideramos al egoísmo/narcisismo como una defensa de los jóvenes para aminorar su sufrimiento subjetivo frente a una cultura que no crea lazos sino, por el contrario, genera masificación con las políticas de consumo (alienación) y/o rivalidad entre los semejantes que pasan a tener las características de extranjeros.

\section{Argumentación teórica}

Cada época sociohistórica genera en el hombre un malestar en la cultura diferente. Trataremos de reflexionar sobre el propio del hipercapitalismo con relación al tránsito de la juventud hacia la adultez.

Observamos que el joven de nuestros días está muy centrado en sí mismo, con una actitud netamente egoísta, sin poder tejer un entramado social de solidaridad entre los semejantes. Muchas veces se cualifica peyorativamente este nivel de egoísmo sin reflexionar acerca del grado de sufrimiento que conlleva. Sin embargo, los que nos dedicamos a la clínica, tenemos cierta preocupación por las patologías llamadas actuales que presentan los jóvenes del Siglo XXI (conductas adictivas, pasajes al acto, enfermedades psicosomáticas, ataques de pánico, etc.). Tomamos al narcisismo (Freud, 1999) (complemento libidinoso del egoísmo) como eje de estas patologías, emergentes del mal-estar en la cultura de hoy. Junto a Bleichmar (2000) pensamos que hoy nuestros jóvenes padecen de un malestar sobrante dado por la imposibilidad de generar un proyecto trascendente, es decir, no pueden imaginar que en un futuro va a disminuir el malestar actual. Afirmamos entonces que lo que permite al hombre soportar el malestar en la cultura es engendrar la esperanza, como ilusión de una vida futura donde reinará la felicidad. Esto posibilita encontrar un camino que justifique el pesar en el presente, pero con la visión de un horizonte más promisorio. 
En nuestros días es difícil que los jóvenes puedan proyectarse en un futuro y, mucho menos, alimentar la esperanza de un futuro mejor. El futuro es un mar revuelto de incertidumbres. Tratan de obtener los mayores recursos que la formación técnica/científica les puede ofrecer, para remar en la tempestad de un mundo donde cada vez hay más excluidos. La angustia permanente con la que conviven es el temor al fracaso (que muchas veces ya han visto en sus mayores), con el pánico de resultar incompetentes para los requerimientos que exige el mercado laboral.

Sabemos a partir de la psicodinamia del trabajo de Desjours (2006) que el trabajo define la identidad del sujeto de nuestros días (el ser se define por el hacer), y es en la autorrealización donde el sujeto afirma su identidad, autoafirmación que se procesa en

el camino hacia la adultez. Es tal el miedo al fracaso y el deseo de éxito correlativo, que el joven ingresa en una lucha por su propia supervivencia, que ve peligrada permanentemente. En esta lucha, el otro, más que un semejante es un rival, por lo que difícilmente pueda tejer con él una red de solidaridad. Es una cultura que arroja al sujeto a la propia soledad y responsabilidad sobre su futuro, a su proactividad y capacidad técnica/científica, que le exige una constante preocupación egoísta para seguir en la rueda del progreso sin fin, que en el caso de bajarse, conllevaría el peor de los sufrimientos humanos: la exclusión social. Tal como plantea Bauman (2012) los profesionales noveles se encuentran con un mercado laboral saturado y al buscar trabajo, tienen que incluirse muchas veces en puestos de menor jerarquía a la que aspiran y para lo que tanto se han esforzado. Es por eso que toman el empleo como algo transitorio y continúan su búsqueda incansable en el mercado global.

El joven se esmera por tener una buena formación, que resulte competitiva. Esta preocupación es tan intensa que no queda espacio para otras, por ejemplo, muchas veces implica la decisión de postergar su proyecto de paternidad/maternidad. Afirmamos esto apoyados en una investigación exploratoria realizada por el mismo equipo de investigadores del INSOD (UADE) sobre las parejas DINKS (20) 2 .

En estos años de juventud, el eje se centra en el desarrollo de carrera como único objetivo para sobrevivir en la sociedad de consumo y lograr su propia independencia económica. Al mismo tiempo no desconocen la experiencia de sus mayores, que en muchos casos han sufrido situaciones de desempleo y/o situaciones de quiebras económicas. Esto propicia una lucha esmerada, llena de esfuerzos, para lograr un bienestar económico a través de su carrera profesional.

\footnotetext{
2 DINKS. Doble income no kids. Son parejas de profesionales, con altos ingresos ambos, que priorizan el consumo de alta gama (tecnología, viajes exóticos, ropa y muebles de diseño) y relegan la conformación de una "familia tradicional" en lo inmediato. Esta decisión de postergar o decidir no conformar una familia con hijos, como se observa en países desarrollados como Canadá, Japón, España, Italia, y EEUU y en potencias emergentes como China implica un cambio en la conformación social de la población. Este cambio podría ocasionar dentro de algunos años una merma en la población activa profesional, por lo que tendría consecuencias demográficas, económicas y sociales.
} 
Frente a esta angustia de poder proyectar un futuro independiente, sostienen el valor del esfuerzo que deviene de la modernidad, como vía para lograr el éxito, metas laborales y personales. Este grupo de jóvenes bregan por superarse y alcanzar el reconocimiento social a partir de su estudio. Toman la vida como un desafío permanente donde tienen que pelear constantemente para lograr su propia supervivencia. Se muestran autosuficientes en sus decisiones y creen que pueden resolver los conflictos autónomamente. Esto muestra que su "egoísmo" está fundado en una visión omnipotente de sí mismos como contracara del terror y la impotencia que los inunda; una sociedad que no les brinda otro mensaje que el de la competitividad o, mejor dicho, la rivalidad con el prójimo para lograr su inclusión.

Acordamos con el planteo de Aulagnier (2003) con respecto al contrato narcisista que sella la sociedad con el infans, brindándole un lugar desde antes de su nacimiento. Para aclarar el concepto de "contrato narcisista" diremos que el mismo se firma entre el niño y el grupo social de pertenencia. El grupo le ofrece al niño un lugar antes de su nacimiento y el niño se compromete con el grupo a formar parte de él, con marcas identificatorias que condicionaran su pensamiento y su accionar.

Ahora bien, la economía neoliberal crea un mundo donde la inclusión/exclusión se convierten en un riesgo permanente; se pone en peligro este contrato narcisista al quebrarse el valor de "justicia social". Este valor se funda según Freud (1999), en la necesidad del niño de eliminar los privilegios individuales para que todos los hombres tengan los mismos derechos y obligaciones. La justicia social significa que la persona renuncia a ciertas satisfacciones egoístas para que los otros hombres renuncien también a ellas o, lo que es lo mismo, no puedan exigir privilegios. Esta exigencia de igualdad es la raíz de la conciencia moral y social así como también del sentimiento del deber. El concepto responde al mito de la Horda Primordial que retoma Freud de la explicación que da Darwin como origen de la sociedad, donde a partir del asesinato del Padre Primordial, la fratría se consolida creando la ley de prohibición del incesto, ley que regula las relaciones sociales y organiza la sociedad.

Trabajaremos fundamentalmente con el tema de la rivalidad y competitividad que se exige hoy para permanecer en el grupo de los incluidos. La sociedad neoliberal rompe el contrato narcisista del que hablamos, bajo la amenaza permanente de exclusión. Nos preguntamos si la cultura de la excelencia, que le exige al hombre siempre un poco más para poder "pertenecer", no hace que el sujeto convierta su energía dirigida al exterior para "ganar" (podemos decir un lugar dentro de la sociedad), en un proceso interior que a veces puede terminar en una entrega sacrificial de sus logros profesionales y hasta del propio yo. Esta reflexión apunta a comprender el porqué de las nuevas patologías que comentamos en la Introducción de este capítulo y que justamente son dadas en llamar patologías narcisistas. Es decir que el joven se ve 
obligado, para poder sobrevivir, a poner toda su energía en sí mismo, produciendo inevitablemente un grado de enfermedad mental.

También en esta línea de pensamiento podríamos entender el porqué del hedonismo, la preocupación por la imagen estética, el deseo del cuerpo perfecto, etc. Es decir, el joven trata de esforzarse para llegar a ser el modelo ideal que le propone la sociedad actual, netamente individualista y alienado a la sociedad de consumo. El consumo desde ya es individual, no es algo que se comparte con otros (Bauman, 2012). Desde la perspectiva sociológica de Durkheim (2004), podríamos plantear que la persona de la actualidad, en las grandes urbes, padece de un estado de anomia. El problema de la anomia se suscita porque los individuos tienen una moral que surge de sus estructuras familiares y religiosas que no les sirve en el ámbito socioeconómico y político actual. Son normas obsoletas o contradictorias respecto de las que propone el mercado.

La anomia es una patología de la estructura social que resulta irreversible ya que es la propia sociedad la que propone el individualismo y esto implica la desorientación moral, el individuo no sabe cómo debe comportarse en cada situación porque tiene valores y normas alternativas incluso contradictorias entre sí.

La anomia (a: prefijo negativo, sin; nomia: normas) significa entonces desorientación moral. No es que falte la moral, sino que hay una inexistencia de las normas apropiadas. Para Durkheim (2004) en la sociedad industrial, las instituciones como la familia o la religión han perdido importancia y con ellas, la solidaridad orgánica. El estado no genera las normas necesarias para regular cada uno de los aspectos de la vida social, sino sólo aquellas que regulan su propia actividad, fomentando así, las actitudes egoístas.

Las contingencias y los riesgos que surgen en la vida cotidiana no pueden ser enfrentadas con las normas, valores y rutinas que fueron heredadas de las generaciones anteriores. Las instituciones que en la Modernidad se encargaban de brindar un orden y una promesa de garantías para la supervivencia social de los hombres, hoy aparecen siendo no fiables. Esto genera una gran decepción, que se refleja en los participantes que plantean no creer en la política y mucho menos en los políticos, ya que ellos, en vez de preocuparse por el bien común, se dedican a trabajar para satisfacer intereses personales (Bauman, 2012). A pesar de dar importancia al establecimiento de normas que debieran organizar la sociedad, plantean que las mismas no pueden cumplirse, y que cada uno sabe lo que está bien o mal y se maneja con sus propias reglas.

Estamos atravesando una crisis social y, por todo la antedicho, el sujeto no puede sino quedar inmerso con todo su ser en ese proceso social. El término crisis significa ruptura, discontinuidad, es decir pérdida o 
ausencia de referentes, resulta así una desestructuración del orden previo sin que lo nuevo pueda tener un perfil organizado, ya que se presenta como ambiguo, indefinido, no resulta sostén. De esta manera:

la multidimensionalidad de la crisis social se expresa, entre muchos signos, por un deterioro acelerado de las instituciones de este sistema, lo que puede aparecer como caducidad súbita de normas y valores, desorganización de la representación del mundo, fisuras y replanteos sustanciales en la significación de sí y de los otros (Quiroga, 1998, p. 21).

Los jóvenes tienen como valor importante la libertad. En verdad este valor siempre implica una tensión para el sujeto entre la dependencia y la independencia, el sometimiento y la soledad. Afirmamos junto a Bleichmar (2000) que no se puede pensar la libertad sin un proyecto a futuro y que hoy hay un vacío representacional para poder catectizarlo.

Este vacío se genera desde el ideal proyectado por los propios padres del joven. El deseo parental que les transmiten es que puedan sobrevivir económicamente, esforzándose para encontrar un lugar en el mercado laboral. Esto significa que estudiar no tiene un valor simbólico sino que es un medio para acceder a posibilidades de supervivencia. Encontramos que el $42 \%$ de los encuestados dicen que el objetivo de estudiar se relaciona con la posibilidad de encontrar mejores ofertas laborales. Por eso planteamos que este mensaje se relaciona con necesidades autoconservativas. Se acompaña, en la inmediatez, de la búsqueda de placeres inmediatos, que provienen fundamentalmente del consumo, especialmente de proyectos mediatos con tinte de libertad relacionados fundamentalmente con los viajes de placer.

Pensamos entonces que el valor de "libertad individual" que la posmodernidad "vende", no es más que el reverso de la masificación que genera bajo la promesa ilusoria de que el "tener" permita "ser" una persona respetable, pertenecer a la globalidad tecnológica, etc. Sin embargo, coincidimos con Fromm (1978) en que cuando la existencia del hombre está condicionada por el "ser" se origina una sociedad interesada fundamentalmente en las personas, en cambio, cuando el eje esta puesto en el "tener" el hombre se preocupa por las cosas más que por sus semejantes, con quienes compite, tornándolos rivales.

El hombre se ve llevado a un estado de sobreadaptación social que es el desconocimiento por parte del sujeto de sus propias necesidades, potencialidades, sentimientos, historia y relaciones interpersonales, con el objetivo de lograr el sentimiento de pertenencia social.

La persona y sus actuaciones van inhibiendo la posibilidad de pensamiento simbólico del sujeto con el consecuente empobrecimiento psíquico y el terror de la destrucción del sí mismo. La solución mágica es la 
búsqueda inagotable de satisfacciones sustitutivas en el mercado de consumo, como si el "tener" fuera el ropaje necesario para vestir al empobrecido "ser".

La caída de las ideologías, de la fe religiosa, ha gestado una cultura donde el bien supremo, es el dinero. Una cultura en la que crece día a día la violencia, paralelamente o mejor dicho como efecto de la injusticia social.

Por eso...cuando la guerra desnuda su obscenidad pulsional (de dominio, de apoderamiento, de destrucción), el sujeto se divide en la esquizia de la creencia, la buena forma de la imagen, para refugiarse en su manto de irrealidad. Escapa de la violencia real en la realidad virtual, como modo de no saber sin olvidar (Pujó, 2006, pp. 40-41)

Los que no logran realizar esta sobreadaptación, y no pueden elaborar su angustia frente al pánico de la exclusión presentan conductas violentas socialmente como única forma de combatir al "otro", que se convierte inexorablemente en su enemigo.

Otra posible salida psicopatológica es la melancolía, es decir, la ruptura por parte del sujeto de todos los lazos sociales, su aislamiento, tristeza y desesperación.

Sin llegar a la psicopatología, nos encontramos con los jóvenes de nuestra muestra que se esfuerzan por tratar de incluirse en los mercados (laboral y de consumo), con una alta preocupación por su propia subsistencia, característica que determina sus rasgos egoístas/narcisista.

Pensamos la salud mental como un conjunto de procesos psicológicos que se construyen a partir de la relación del sujeto consigo mismo y con el mundo externo, desde un permanente pensamiento crítico. La persona crea y se recrea en su actividad laboral, a esto lo llamamos sublimación.(Freud,1996).

Por lo tanto consideramos que la característica de egoísmo, que responde al narcisismo secundario, es una defensa regresiva del joven, frente a la gran frustración y a las exigencias de "perfección", de "cero defecto" que exige el hipercapitalismo para sobrevivir y ser incluido en los mercados, única forma de pertenecer a la sociedad.

\section{Conclusión}

Pensamos que el joven tiene como rasgo característico de personalidad el egoísmo/narcisismo, pero que éste resulta del intento de sobrevivir en un marco social despiadado que no le garantiza una red social de 
continencia. El hipercapitalismo excluye a los sujetos que no logran sobreadaptarse a sus exigencias tanto laborales como de consumo.

El sujeto queda des/sujetado de sus raíces identitarias, los mayores no resultan modelos ideales a seguir, no pueden sembrar la esperanza imaginaria para proyectar su bienestar con acciones concretas en el futuro. Así es como el valor de la libertad, rasgo evolutivo preponderante del período adolescente, solo puede arraigarse en la fantasía de metas individuales de placer como el viajar, conocer "otros mundos y culturas diferentes" al decir de algunos de los entrevistados, tal vez con la expectativa de encontrar modelos de felicidad y bienestar en otra parte.

No es que carezcan de moral, diferencian lo que está bien de lo que está mal, pero al no confiar en las autoridades representativas del poder democrático, no legitiman las normas establecidas, refiriendo el $88 \%$ de nuestros encuestados que las normas no se pueden cumplir. Esto implica que la juventud actual no se encuentra amparada socialmente por ninguna de las instituciones, ya que no creen que propicien la equidad social. Así es como no terminan de dejar un sentimiento endogámico, y resurge la necesidad del apego parental (Bowlby, 1998).

La familia de origen sigue siendo, como en la niñez, un lugar de refugio y continencia afectiva/económica. Si bien manifiestan el deseo de una vida autónoma e independiente económicamente, los padres, aunque no resultan referentes ideales, sí guardan el lugar de protección y seguridad en un mundo que solo los envuelve en un torrentoso mar de incertidumbres y amenaza permanentemente con la posibilidad de exclusión. Sumidos en la necesidad de sobrevivir en un mundo que parece regido por la "ley de la selva", no queda espacio para pensar en el semejante, solo los motiva la necesidad de supervivencia, que remite al egoísmo/narcisismo.

Esta lucha por la subsistencia, por la independencia, por encontrar un "lugar en el mundo" de reconocimiento social, hace que el joven instrumente defensas como la desmentida que lo llevan a saber y al mismo tiempo no saber, el dolor que provoca la injusticia social, la violencia acrecentada en la sociedad, Sin embargo como efecto de ello observamos síntomas endémicos como las adicciones a diferentes objetos (trabajo, gimnasio, sustancias, internet, etc.), ataques de pánico, autoagresiones, conductas compulsivas, etc.

Lo que queremos remarcar es que el egoísmo/narcisismo del joven del grupo etario seleccionado, es producto de la sociedad hipercapitalista que rompe los lazos sociales al proponer una cultura donde la inclusión social tiene que ver con el "tener" para "pertenecer". Quedan así invertidos los términos generándose un nuevo mandato social, donde el vínculo con el otro no es lo privilegiado como valor ético sino la masificación del hombre bajo la égida del mercado de consumo. 
En síntesis, la persona desarrolla en el escenario social, el deber ser, tras la búsqueda inagotable de aprobación e inclusión social. Sin embargo, al pensar al hombre como producido/productor del orden social, debiéramos considerar el interjuego dialéctico entre la persona y el sí mismo.

El escenario social no tiene por qué ser simple repetición de lo mismo. Los escenógrafos recrean el mobiliario en función de su creatividad y de la potencialidad de sus actores. La concepción del teatro hoy es el diálogo con el público, la interacción entre actores y observadores que comparten la acción (Goffmann,1997).

Sólo mediante la identificación recíproca el hombre podrá desarrollar una actitud desalienante, rompiendo su aislamiento, creando nuevas formas de redes sociales que le permitirán crear una relación intrínseca entre representación, acción y realidad externa. Así el sujeto accederá al conocimiento de sí y del otro, al reconocimiento de sus propias necesidades, reapropiándose (en la escena social) de su sí mismo.

El “orden social” existe con independencia del sujeto, está dado para él desde antes de su nacimiento, pero el hombre es su potencial transformador a partir de su capacidad creativa. Pensamos tal como planteaba Pichon Riviere (1985) que para que nuestros jóvenes puedan tener una actitud más solidaria, el orden social debería permitir planificar la esperanza. 


\section{Referencias bibliográficas}

ALAUGNIER, P. (2003) La violencia de la interpretación. Buenos Aires: Amorrortu.

BAUMAN, Z. (2012). Esto no es un diario. Buenos Aires: Paidós

BLEICHMAR, S. (2000). La Subjetividad en riesgo. Buenos Aires: Amorrortu.

BOWLBY, J. (1998). La teoría del apego. Buenos Aires: Paidós.

DEJOURS, C. (2006). La banalización de la injusticia social. Buenos Aires: Topia.

DURKHEIM, S.L. (2004). El suicidio, estudios sobre sociología. Buenos Aires: Losada.

FREUD, S. (1999). Introducción al Narcisismo. En Obras Completas (1914) Vol. 14. Buenos Aires: Amorrortu.

---. (1999). Psicología de las masas y análisis del yo. En Obras Completas (1921) Vol. 18. Buenos Aires:

Amorrortu.

---. (1999). El malestar en la cultura. En Obras Completas (1930) Vol. 21. Buenos Aires: Amorrortu.

GIL CALVO, E. (1993). Futuro incierto. Barcelona: Anagrama.

GOFFMAN.I. (1997). La presentación de la persona en la vida cotidiana. Buenos Aires: Amorrortu Editores. MELMAN, Ch. (2005). El hombre sin gravedad. Rosario: UNR Editores.

PICHON RIVIÈRE, E. (1985). El proceso grupal: Del psicoanálisis a la psicología social. Buenos Aires: Nueva Visión.

PUJÓ, M. (2006). Para una clínica de la cultura. Buenos Aires: Gama, pp. 40-41.

QUIROGA, A. (1998). Crisis, procesos sociales, sujeto y grupo. Buenos Aires: Cinco, p. 21 